\title{
Designation of Strain H37Rv as the Neotype of Mycobacterium tuberculosis
}

\author{
GEORGE P. KUBICA, THOMAS H. KIM, and FRANK P. DUNBAR \\ Trudeau Institute, Inc., P.O. Box 59, Saranac Lake, New York 12983
}

\begin{abstract}
Strain H37Rv of Mycobacterium tuberculosis (Zopf) Lehmann and Neumann is typical of the species in growth characteristics, drug susceptibility, and biochemical activity. H37Rv is compared with the hypothetical median strain of $M$. tuberculosis and agrees with it in 70 of 71 characters. In comparison with other strains of tubercle bacilli, H37Rv has moderate virulence for guinea pigs and mice. This strain agrees well with Koch's original description of the tubercle bacillus; the few differences that do exist are discussed. The well documented history of H37Rv, coupled with its world-wide distribution and long use by mycobacteriologists, makes it most appropriate as the neotype of the species $M$. tuberculosis. The strain may be obtained from the Trudeau Institute, Inc., Saranac Lake, N.Y. 12983, as TMC 102 or from the American Type Culture Collection, Rockville, Md. 20852, as 27294.
\end{abstract}

In 1967, Runyon et al. (25) published species descriptions for Mycobacterium tuberculosis (Zopf) Lehmann and Neumann, $M$. bovis Karlson and Lessel, and $M$. microti Reed. In this publication, strain $\mathrm{H} 37 \mathrm{Rv}$ (32) was proposed as the neotype of the species $M$. tuberculosis. Because the publication by Runyon et al. (25) did not meet the requirements for the designation of a neotype (5) and because there was only minimal information regarding the in vitro characteristics, pathogenicity, and maintenance of virulence of strain H37 Rv, it was deemed necessary to designate properly the neotype of $M$. tuberculosis and to describe fully its properties. Furthermore, the use of strain H37Rv as the "standard" for $M$. tuberculosis in taxonomic studies, drug susceptibility testing, and pathology-immunology experiments has resulted in the world-wide distribution of this strain to the extent that it is maintained by virtually every mycobacterial culture collection in existence. Unfortunately, through lack of knowledge or experience, many cultures of $\mathrm{H} 37 \mathrm{Rv}$ no longer are virulent for their common laboratory animal hosts. It is hoped that this publication will clarify the problem of maintenance of virulence, especially as it pertains to this widely used and newly designated neotype.

It is not intended that the species description of $M$. tuberculosis as detailed in the present and forthcoming issues of Bergey's Manual or the publication by Runyon et al. (25) be reiterated here. Rather, we will concentrate on the history, in vitro characteristics, and virulence for mice and guinea pigs of the neotype in comparison to other strains of $M$. tuberculosis.

\section{MATERIALS AND METHODS}

Strain H37Rv. M. tuberculosis strain H37 was isolated from a human patient in 1905 by $E$. R. Baldwin, Trudeau Sanatorium, Saranac Lake, N.Y. (32). The early studies of Steenken et al. (32) revealed that this strain could dissociate into avirulent and virulent colony forms. Strangely enough, the terms first used to describe these variants were " $R$ " and " $S$," but these letters did not refer to the words rough and smooth commonly used to describe colonial variants; instead the terms were used to describe those variants resistant (R) or susceptible (S) to the environment of the culture medium, even though both colonial variants were rough. If the original designations had persisted, the virulent variant of the neotype strain would be H37S. Fortunately, however, the inapt choice of the letters $R$ and $S$ was realized, and Steenken (28) changed the designation of the virulent variant from $\mathrm{S}$ to $\mathrm{Rv}$ (for rough virulent). In a subsequent publication (23) the full designation $\mathrm{H} 37 \mathrm{Rv}$ was used for the first time, and the virulence of this variant was compared with that of the avirulent colony form (H37Ra).

Maintenance of $\mathbf{H 3 7 R v}$. For the past 3 years, strain $\mathrm{H} 37 \mathrm{Rv}$ has been maintained at the Trudeau Institute as a frozen suspension $(-70 \mathrm{C})$ in the phosphatebuffered $(0.067 \mathrm{M}, p \mathrm{H} 6.8)$ gelatin (1\%). Prior to this time it was maintained by routine passage of pellicle growth at 10 to 14 day intervals on the surface of Proskauer and Beck (PB) medium.

Because there are many modifications of the PB formula in existence, the medium as used in this 
institute is described below. PB medium: monopotassium phosphate, $5.0 \mathrm{~g}$; asparagine, $5.0 \mathrm{~g}$; magnesium sulfate $\cdot 7 \mathrm{H}_{2} \mathrm{O}, 0.6 \mathrm{~g}$; magnesium citrate, $2.5 \mathrm{~g}$; gly cerol, $20.0 \mathrm{ml}$. and distilled water, $1,000.0 \mathrm{ml}$.

Dissolve the above ingredients in order, being certain each compound is solubilized before the next is added. Adjust $p \mathrm{H}$ to 7.8 by the addition of $40 \%$ $\mathrm{NaOH}$ (about 3.5-5.0 ml/liter). Autoclave at $15 \mathrm{psi}$ $(121 \mathrm{C})$ for $15 \mathrm{~min}$, after which the $p \mathrm{H}$ should be 7.4 . Filter the medium to remove any precipitate, bottle in desired volumes, and autoclave again at 15 psi $(121 \mathrm{C})$ for $15 \mathrm{~min}$.

Methods. In 1968, a contract was negotiated with the National Institute of Allergy and Infectious Diseases to expand the Trudeau Mycobacterial Culture (TMC) Collection to contain highly characterized representatives of species of mycobacteria demonstrated to have biomedical significance. Currently, the collection is comprised of 150 strains representing 25 species of mycobacteria. To characterize these organisms for taxonomic purposes, it has been necessary to utilize a number of in vitro tests, descriptions of which follow.

Arylsulfatase activity was determined by the method of Jones et al. (11), and any activity of \pm , or greater, was recorded after 3 days, 2 weeks, and 5 weeks.

Character 1:3 days, arylsulfatase positive.

Character 2:2 weeks, arylsulfatase positive.

Character 3:5 weeks, arylsulfatase positive.

Catalase activity was measured both at room temperature (semiquantitative test) and after heating culture suspensions to $68 \mathrm{C}$, by the methods of Kubica et al. $(20,21)$.

Character 4 :semiquantitative, catalase negative.

Character 5 :catalase positive, greater than $45 \mathrm{~mm}$

foam.

Character 6:catalase positive after heating at $68 \mathrm{C}$ for $20 \mathrm{~min}$.

Dye susceptibility tests, by the methods of Jones and Kubica $(10,13)$, were slightly modified. All dyes were incorporated into Dubos oleic acid-agar at 10 $\mathrm{mg} \%$ (corrected for dye content).

Character 7:growth on biebrich scarlet.

Character 8:growth on eosin Y.

Character 9:growth on MacConkey agar.

Character 10: growth on malachite green.

Character 11:growth on methyl violet.

Character 12: growth on pyronin B.

Growth in the presence of hydroxylamine was performed by adding recommended concentrations of this compound (36) to American Trudeau Society (ATS) medium (43).

Character 13:growth on $125 \mu \mathrm{g}$ of hydroxylamine.

Character 14:growth on $250 \mu \mathrm{g}$ of hydroxylamine.

Character 15:growth on $500 \mu \mathrm{g}$ of hydroxylamine.

Sodium chloride tolerance was performed as described by Kestle et al. (15).

Character 16:growth on $5 \% \mathrm{NaCl}$.

Nicotinamide tolerance (9) was performed by adding $0.5 \%$ nicotinamide to ATS medium (43).

Character 17:growth on nicotinamide.

Nitrite inhibition test was performed as described by Abbott et al. (1).
Character 18: growth on $0.013 \mathrm{M}$ nitrite.

Character 19:growth on $0.025 \mathrm{M}$ nitrite.

Growth on $0.1 \%$ picric acid was determined on Dubos oleic acid-agar medium containing $0.1 \%$ picric acid, a modification of the method of Tsukamura (36).

Character 20 :growth on $0.1 \%$ picric acid.

The oleate tolerance test of Wayne et al. (41) was modified according to Kestle et al. (15).

Character 21 :growth on $0.025 \%$ oleate.

Character 22: growth on $0.05 \%$ oleate.

Character 23 :growth on $0.1 \%$ oleate.

Growth and degradation of $p$-aminosalicylate (PAS), $p$-aminobenzoate (PABA) and salicylate (SAL) as proposed by Tsukamura (36), was modified by adding the recommended concentrations of PAS and SAL and $0.2 \%$ PABA to ATS medium (43).

Character 24:growth on PABA.

Character 25:degradation of PABA.

Character 26: growth on PAS.

Character 27:degradation of PAS.

Character 28:growth on SAL.

Character 29:degradation of SAL.

Growth after exposure to $60 \mathrm{C}$ for $4 \mathrm{hr}$ was determined as described by Gordon and Smith (7) except that Löwenstein-Jensen egg medium was used in place of glycerol agar slants.

Character 30:growth occurs after heating culture to $60 \mathrm{C}$ for $4 \mathrm{hr}$.

Iron uptake was investigated by the method of Szabo and Vandra (35).

Character 31 :iron uptake positive.

The niacin test was performed as described by Runyon et al. (26).

Character 32:niacin positive.

Nitrate reduction was detected as described by Virtanen (38).

Character 33:nitrate reduced.

Nitrite reduction was investigated by the method of Wayne and Doubek (39).

Character 34:nitrite reduced in 7 days.

Character 35 : nitrite reduced in 14 days.

The tellurite reduction test was performed as described by Kilburn et al. (16).

Character 36:tellurite reduced in 3 days.

Character 37:tellurite reduced in 6 days.

Character 38:tellurite reduced in 10 days.

Hippurate hydrolysis was studied as described by Gordon (6).

Character 39:hippurate hydrolyzed.

Tween hydrolysis was detected as described by Wayne and Doubek (40).

Character 40:Tween hydrolyzed in 5 days.

Character 41 : Tween hydrolyzed in 10 days.

The Tween opacity test was performed according to Wayne et al. (41), except that the first reading was at 2 weeks rather than 1 week.

Character 42:Tween opacity produced in 2 weeks. Character 43: Tween opacity produced in 5 weeks. Pigment production was recorded as described by Runyon (24).

Character 44 : culture photochromogenic.

Character 45: culture scotochromogenic.

Character 46: culture nonphotochromogenic. 
Temperature of growth was determined by inoculating a 100 - to 1,000 -fold dilution of a barely turbid suspension of the organism in question on the surface of six Löwenstein-Jensen egg slants. Each slant was placed in an incubator of known temperature $( \pm 1 \mathrm{C})$.

Character 47:growth occurs at $19 \mathrm{C}$.

Character 48:growth occurs at $25 \mathrm{C}$.

Character 49: growth occurs at $32 \mathrm{C}$.

Character 50:growth occurs at $37 \mathrm{C}$.

Character 51:growth occurs at $45 \mathrm{C}$.

Character 52:growth occurs at $52 \mathrm{C}$.

Drug susceptibility genetic markers were investigated by a combination of the methods of Vestal and Kubica (37), Kubica and Dye (18), Steenken (2), and Stottmeier et al. $(33,34)$.

Character 53:culture grows on $10 \mu \mathrm{g}$ of amithiozone.

Character 54 :culture grows on $10 \mu \mathrm{g}$ of thiophen-2carboxylic acid hydrazide.

Character 55:culture grows on $400 \mu \mathrm{g}$ of triphenyl tetrazolium chloride.

Character 56:culture grows on $5 \mu \mathrm{g}$ of isoniazid.

Character 57:culture grows on $10 \mu \mathrm{g}$ of streptomycin.

Character 58:culture grows on $10 \mu \mathrm{g}$ of $p$-aminosalicylate.

Character 59:culture grows on $50 \mu \mathrm{g}$ of viomycin.

Character 60:culture grows on $50 \mu \mathrm{g}$ of kanamycin.

Character 61 :culture grows on $50 \mu \mathrm{g}$ of cycloserine.

Character 62:culture grows on $10 \mu \mathrm{g}$ of ethionamide.

Character 63: culture grows on $12 \mu \mathrm{g}$ of ethambutol.

Character 64 : culture grows on $5 \mu \mathrm{g}$ of rifampin.

Character 65:culture grows on $50 \mu \mathrm{g}$ of pyrazinamide.

Colony morphology on oleic acid-albumin-agar was studied as described by Kubica and Jones (19) and Jones and Kubica (12). Incubation was at $37 \mathrm{C}$ for 3 weeks. Five classes of colony ty pes were recorded.

Character 66: colonies rough, wrinkled, corded.

Character 67:colonies smooth, transparent, entire or lobed edges.

Character 68:colonies smooth, domed, opaque, entire edge; some with aerial hyphae.

Character 69:colonies smooth, raised, with dark central spot.

Character 70:colonies smooth to rough with varying amount of peripheral filaments.

Speed of growth was determined at the optimal temperature of growth (see characters 47-52).

Character 71 :growth in less than 7 days.

\section{RESULTS AND DISCUSSION}

The collection contains 39 strains of $M$. tuberculosis which may be roughly divided into three groups: strains susceptible to all drugs, strains resistant to isoniazid, strains resistant to drugs other than isoniazid. Within each of these groups are found guinea pig-virulent and -avirulent variants. After all 39 strains had been examined by the above 71 characters, a hypothetic median strain (HMS) pattern (22) was established for the species $M$. tuberculosis. For purposes of comparison, the in vitro characteristics of strain H37 Rv [TMC 102; American Type Culture Collection (ATCC) 27294] are compared to the HMS (Table 1), and it can be seen that this strain has a $99 \%$ similarity to the HMS, differing only in 1 out of 71 characters $(\mathrm{H} 37 \mathrm{Rv}$ was positive in tellurite reduction at 6 days, whereas the HMS was not positive until the tenth day). Only one strain (TMC 110) was $100 \%$ like the HMS, whereas three others (TMC 116, 124, 322) showed 99\% similarity like H37Rv. The remainder of the strains showed a range of similarities to the HMS from 90 to $97 \%$.

It was interesting that the 19 strains of tubercle bacilli susceptible to drugs had an average per cent similarity to the HMS of 97.1 ; those resistant to any drug exclusive of isoniazid showed an average similarity of $95.3 \%$ to the HMS, whereas the isoniazid-resistant tubercle bacilli collectively were only $91.4 \%$ similar to the HMS. In the latter instance, resistance to isoniazid was always accompanied by loss of catalase activity, failure to demonstrate arylsulfatase activity at 5 weeks, and commonly by growth on pyronin B; other properties where differences occurred showed no intragroup trend.

Virulence for mice and guinea pigs. The virulence of tubercle bacilli has been the subject of concern among mycobacteriologists for years. Steenken et al. (32) early demonstrated that tubercle bacilli could undergo "forced mutation" to lower levels of virulence, and subsequently Steenken (27) stated that too many passages of tubercle bacilli on a medium of acidic $p \mathrm{H}$ could result in a strain possessing a very low degree of virulence. The fact that most media employed today for primary isolation and maintenance of mycobacteria are acidic may account for the gradual loss in virulence of H37Rv (and other strains of tubercle bacilli). Steenken and Gardner (30) discussed their own experiences in this regard with respect to the H37 strain, and they expressed (29) the strong feeling that growth of tubercle bacilli in a well buffered, completely synthetic medium of alkaline $p \mathrm{H}$ was tantamount to maintenance of virulence.

Despite the extreme care and control of media preparation, culture transfer, animal-passage frequency, etc., the virulence of cultures of $\mathrm{H} 37 \mathrm{Rv}$ has in recent times been quite variable and certainly diminished from that described in earlier reports. The method used here for assessment of virulence of tubercle bacilli in 
TABLE 1. Reaction of hypothetic median strain (HMS) and proposed neotype H37Rv in 71 test characters used to taxonomically characterize mycobacteria ${ }^{a}$

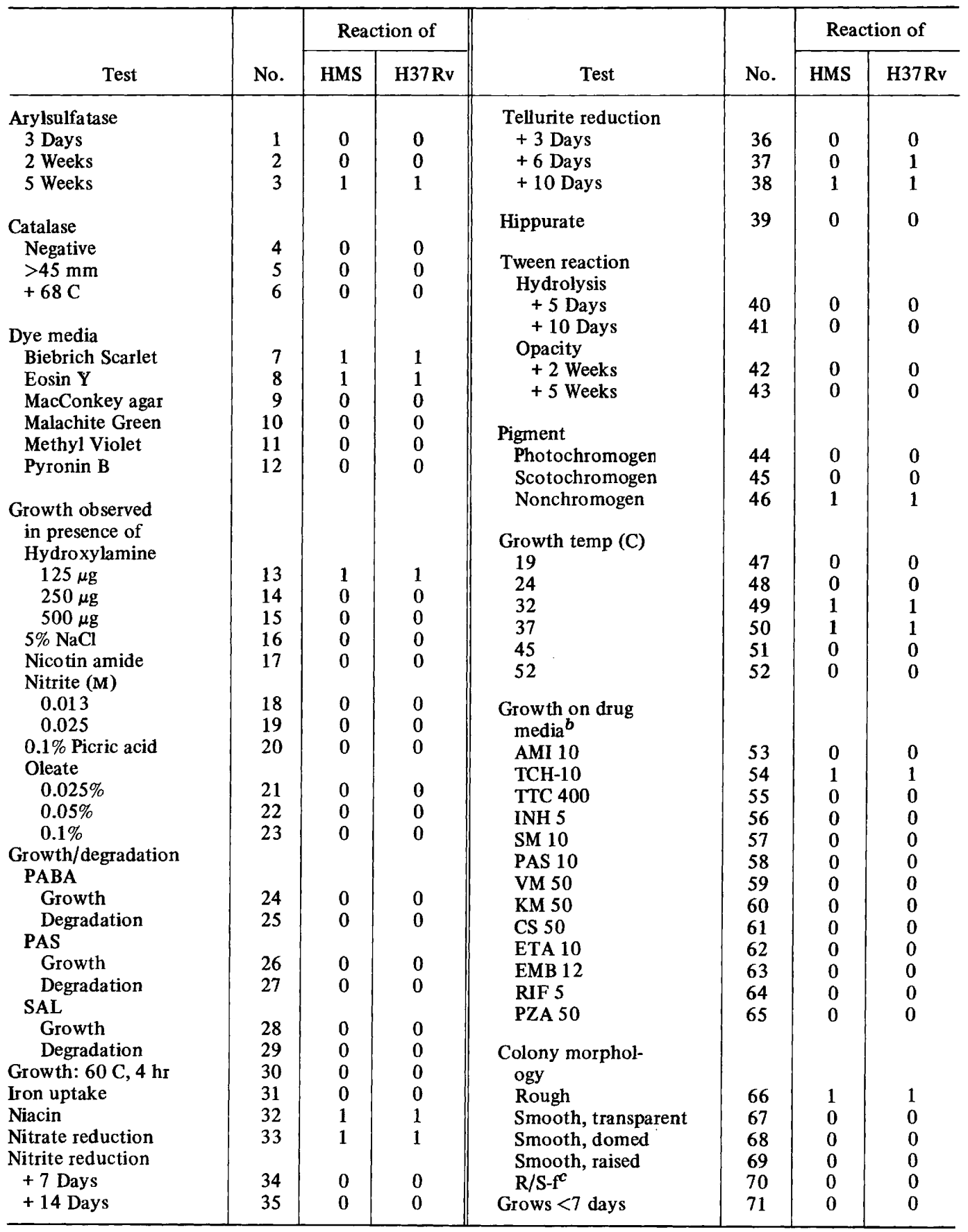

${ }^{a}$ Positive reaction $=1$; negative reaction $=0$. Abbreviations: amithiozone, AMI; thiophen-2-carboxylic acid hydrazide, TCH; triphenyl tetrazolium chloride, TTC; isoniazid, INH; streptomycin, SM; $p$-aminosalicylate, PAS; viomycin, VM; kanamycin, KM; cycloserine, CS; ethionamide, ETA; ethambutol, EMB; rifampin, RIF; pyrazinamide, PZA; $p$-aminobenzoate, PABA; salicylate, SAL.

$b$ Numbers indicate amounts $(\mu \mathrm{g})$ of drug in media.

$c$ Colonies smooth to rough with varying amount of peripheral filaments. 
guinea pigs is a slight modification of the procedure described by Steenken and Gardner (29). As originally described, the extent of tuberculous involvement of the spleen, liver, lungs, and lymph nodes was assigned a value proportional to the extent and severity of the grossly visible disease following the subcutaneous injection of $0.1 \mathrm{mg}$ (ca. $10^{6}$ viable units) of viable tubercle bacilli. The maximal value for any organ was 4, resulting in a total value of 16 for an animal exhibiting advanced generalized tuberculosis. In recent years, the extent of liver involvement has been noted to be minimal, even in heavily diseased animals, so that currently the liver is eliminated from final numerical assessment, resulting in a maximal value of 12 , reflecting involvement only of lung, spleen, and lymph nodes. Although admittedly subjective, this method of virulence assessment is remarkably constant when performed by a person well trained and experienced in its interpretation. There has been a continuity of such personnel at the Trudeau Institute since 1927.

In reviewing the levels of virulence of strain $\mathrm{H} 37 \mathrm{Rv}$ over several decades, it is interesting to note that the studies of Steenken and Gardner (29) showed an average virulence index of 14 out of 16 (this would equal 10.5 on the present scale of 12), a level classified as highly virulent. Review of subsequent publications from the Trudeau Institute showed a gradual, almost imperceptible, drop in virulence index, reaching a level of 11.3 out of 16 (comparable to 8.5 on scale of 12) in a report published in 1959 (31). These observations were brought more sharply to our attention when a routine guinea pig-virulence test of H37Rv in 1969 revealed an index of 7.3 out of 12 , a value regarded as only moderate virulence, and this with an inoculum of ca. $10^{6}$ viable bacillary units.

To prevent still further reduction in virulence pending attempts to select, test, and propagate the more virulent colony form, we have prepared lots of $\mathrm{H} 37 \mathrm{Rv}$, both for seed and distribution, which are stored at $-70 \mathrm{C}(8)$. Our own experience with this storage temperature over a period of 3 years has been extremely rewarding. The cultures have retained not only their viability but also their virulence.

Needless to say, there are other strains of $M$. tuberculosis in our collection which are comparatively more virulent than $\mathrm{H} 37 \mathrm{Rv}$, some with indexes as high as 11 out of $12(3)$, but not much is known about these organisms, and few investigators employ them for their experimental work.

The comparative virulence of $\mathrm{H} 37 \mathrm{Rv}$ in mice (specific pathogen-free CD-1) and guinea pigs
(Trudeau outbred strain) has been reported from this Institute by Collins and Smith (3). This report showed the variability in virulence of different substrains of $\mathrm{H} 37 \mathrm{Rv}$ either returned to this institute by other investigators or as maintained here under different conditions of subculture. With the stock lot of H37Rv stored in a $-70 \mathrm{C}$ deep freeze since 1969 , we have had occasion to infect mice repeatedly, both intravenously and by the airborne route, for various reasons. Figures 1 and 2 show the growth curves for different inocula of H37Rv in

\section{INTRAVENOUS CHALLENGE WITH H37RV}

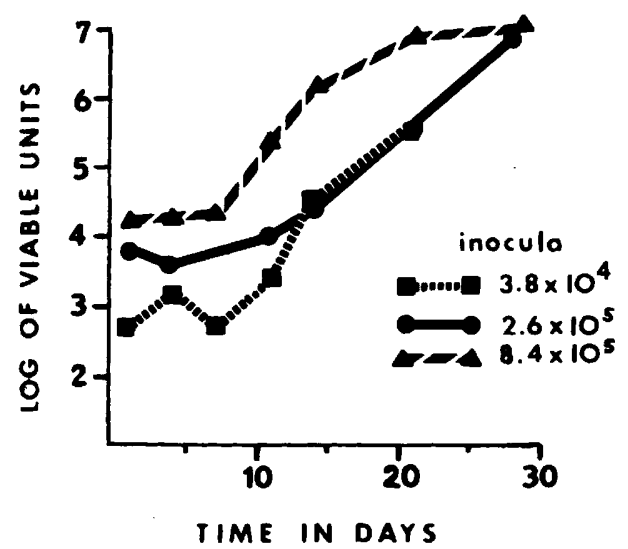

FIG. 1. Growth of $M$. tuberculosis strain H37Rv in the lungs of mice infected by inoculation into the lateral tail vein. Each point on the graph represents the median value of five mice.

\section{AIRBORNE CHALLENGE WITH H37RV}

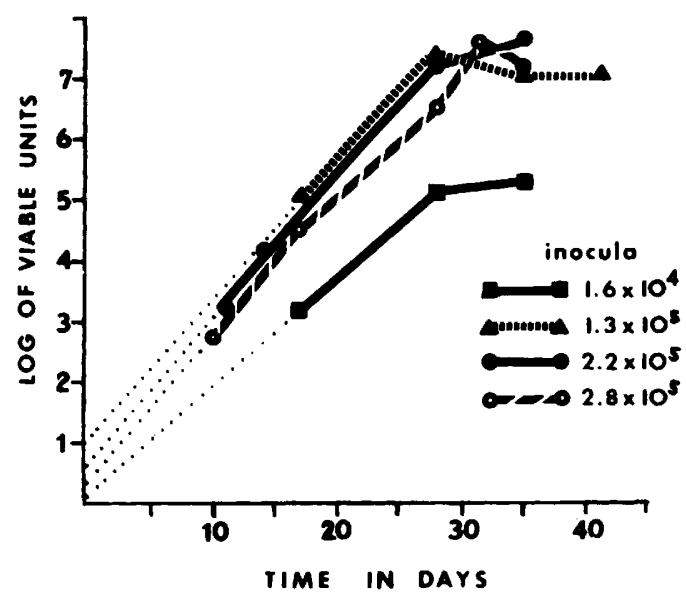

FIG. 2. Growth of M. tuberculosis strain H37Rv in the lungs of mice subjected to infection with small numbers of organisms by the airborne route. Each point on the graph represents the median value of five mice. 
the lungs of CD-1 mice infected either intravenously or by the airborne route.

For all airborne experiments, cultures of $\mathrm{H} 37 \mathrm{Rv}$ were removed from the $-70 \mathrm{C}$ deep freeze, quickly thawed in a $37 \mathrm{C}$ water bath, and diluted to approximately $10^{5}$ organisms per $\mathrm{ml}$ of nebulizing fluid. By extrapolating back to the vertical axis (dotted portion of curves in Fig. 2), it was possible to estimate the actual number of viable bacilli inhaled by an individual mouse. It is interesting that although the curves in Fig. 2 represent a range of over 2 years of experiments, the inhalation of 5 to 10 viable bacilli was still sufficient to establish a final total lung population per mouse of $10^{7}$ viable H37Rv. The extreme reproducibility of results using such small numbers of inocula is ample evidence of the persistence of viability and uniformity of infectivity of suspensions of this organism stored at $-70 \mathrm{C}$.

Comparison of $\mathrm{H} 37 \mathrm{Rv}$ with Koch's original description of tubercle bacilli. It is difficult, if not impossible, to establish unequivocally the relationship of the neotype, $\mathrm{H} 37 \mathrm{Rv}$, with the original tubercle bacillus described by $R$. Koch (17). From Koch's original description, it is obvious that his investigations encompassed studies of not only $M$. tuberculosis but $M$. bovis as well. Koch described the organisms as staining with difficulty and accepting the primary stain (methylene blue in his studies) only after prolonged staining, or with application of mild heat; the bacilli were described as being nonmotile, rod shaped, about five times longer than their width, and about one-fourth to one-half as long as the diameter of a red blood cell $(7-8 \mu \mathrm{m})$, sometimes even equalling the diameter of a red cell. These observations are in agreement with the staining characteristics and size of $\mathrm{H} 37 \mathrm{Rv}(0.3$ to 0.6 by 1-4 $\mu \mathrm{m}$ ) reported by Runyon et al. (25). One of Koch's original observations which is at variance with present knowledge is his report that the stained bacilli contained spores. There seems little doubt that he was referring to granules or beads, described as being either polar or evenly distributed throughout the length of the bacillus (42). Koch also mentioned that when the bacilli are in great numbers they frequently occurred in "braided groups," undoubtedly the phenomenon of cord formation described by Dubos and Middlebrook (4).

Although he used heat-coagulated sheep or cow serum for his initial cultural studies, Koch described growth characteristics of the tubercle bacillus which are strikingly similar to those of $M$. tuberculosis grown on the more complicated culture media of today: growth, appearing first after 10 days as small points of dry-looking scales which enlarge within 3 to 4 weeks, flatten toward the periphery, and do not invade or liquefy the medium; individual colonies crumbly, being crushed only with pressure. The very young colonies viewed at the end of the first week under 30 to $40 \times$ magnification were described by Koch as spindle- or S-shaped formations; decades later these early colonies were described as haphazard bundles of sticks (19). Because tubercle bacilli grew only between 30 and $40 \mathrm{C}$ with optimum at $37 \mathrm{C}$, Koch immediately suggested they were obligate parasites.

In his attempt to convince his listening audience of the cause and effect relationship of tubercle bacilli and phthisis, Koch (17) undertook tremendous investigations in laboratory animals and established therewith the now well known Koch's postulates. It is perhaps in the animal studies wherein we encounter most difficulty in equating H37Rv with Koch's tubercle bacillus for Koch (17) described the lethality of his bacilli for rabbits, an observation at odds with our present concept of $M$. tuberculosis (25) unless large inocula are used. Most of these differences can be reconciled in the light of two observations: (i) Koch's description of the isolation of tubercle bacilli from the calcified, white, pearly nodules in the lungs of cattle with Perlsucht is almost irrefutable evidence of infection with $M$. bovis, an organism known to be highly pathogenic for rabbits (14); (ii) although there is no quantitative designation of the amount of tubercle bacilli injected into rabbits, Koch's description of the "... injection of the same blood serum, in which . . . a crumb of a culture . . . had been suspended," implies a fairly heavy inoculum by today's standards; this statement, taken with his pathologic description of the necropsied experimental animal in which the "... extraordinary number of tubercles was in proportion to the large number of bacilli introduced," suggest that very heavy inocula were used, and this can indeed prove fatal for rabbits (42).

In addition to the rabbit, Koch also reported his new-found tubercle bacilli to produce tuberculosis readily in guinea pigs, mice, and hamsters, and these results are concordant with information presented here and elsewhere (25). The fact that Koch observed minimal or no disease in experimentally infected dogs, rats, hedgehogs, pigeons, and frogs is in agreement with present observations $(25,42)$ whereas the minimal or variable pathology observed in cats was again almost certainly due to the occasional inoculation of this animal with $M$. bovis.

These limited, though detailed, features of 
comparability-staining characteristics, cellular dimensions, colonial morphology, speed of growth, and animal pathogenicity-indicate that the original tubercle bacilli of Koch are indeed those which today are referred to as $M$. tuberculosis, as exemplified by the neotype, H37Rv.

\section{ACKNOWLEDGMENTS}

In proposing $\mathrm{H} 37 \mathrm{Rv}$ as the neotype of the species Mycobacterium tuberculosis, the authors would be remiss not to credit the tremendous contribution to this proposal made possible by William Steenken, Jr. His unflagging zeal in tuberculosis research, and particularly his well-documented and persistent studies on the maintenance of strain H37Rv, stand as testimonial to his five decades of contribution to this field of microbiology. We proudly acknowledge his efforts and propose this neotype in his honor.

This investigation was supported by Public Health Service contract no. PH 43-68-640 from the National Institute of Allergy and Infectious Diseases.

\section{LITERATURE CITED}

1. Abbott, V. D., J. O. Kilburn, W. Harbison, and G. P. Kubica. 1968. Differential identification of mycobacteria. IV. The nitrite inhibition test. Amer. Rev. Resp. Dis. 97:931-934.

2. Collins, F. M., G. B. Mackaness, V. Montalbine, and M. M. Smith. 1968. A comparison of the Steenken minimal inhibitory concentration and the Canetti proportion methods for determining levels of drug resistance in cultures of Mycobacterium tuberculosis. Amer. Rev. Resp. Dis. 98:189-200.

3. Collins, F. M., and M. M. Smith. 1969. A comparative study of the virulence of Mycobacterium tuberculosis measured in mice and guinea pigs. Amer. Rev. Resp. Dis. 100:631-639.

4. Dubos, R. J., and G. Middlebrook. 1947. Media for tubercle bacilli. Amer. Rev. Tuberc. 56:334345.

5. Editorial Board, Judicial Commission of the International Committee on Nomenclature of Bacteria. 1966. International Code of Nomenclature of Bacteria. Int. J. Syst. Bacteriol. 16:459490.

6. Gordon, R. E. 1966. Some strains in search of a genus-Corynebacterium, Mycobacterium, Nocardia or what? J. Gen. Microbiol. 43:329-343.

7. Gordon, R. E., and M. M. Smith. 1953. Rapidly growing, acid-fast bacteria. I. Species' descriptions of Mycobacterium phlei Lehmann and Neumann and Mycobacterium smegmatis (Trevisan) Lehmann and Neumann. J. Bacteriol. 66:41-48.

8. Grover, A. A., H. K. Kim, E. H. Wiegeshaus, and D. W. Smith. 1967. Host-parasite relationships in experimental airborne tuberculosis. II. Reproducible infection by means of an inoculum preserved at -70 C. J. Bacteriol. 94:832-835.

9. Hok, T. T. 1962. A new method for the differentiation of human tubercle bacilli from other types of mycobacteria, using nicotinamidecontaining medium (nicotinamide test). Amer. Rev. Resp. Dis. 86:94.

10. Jones, W. D., Jr., and G. P. Kubica. 1963. The differential typing of certain rapidly growing mycobacteria based on their sensitivity to various dyes. Amer. Rev. Resp. Dis. 88:355-359.

11. Jones, W. D., Jr., V. D. Abbott, A. L. Vestal, and G. P. Kubica. 1966. A hitherto undescribed group of nonchromogenic mycobacteria. Amer. Rev. Resp. Dis. 94:790-795.

12. Jones, W. D., Jr., and G. P. Kubica. 1965. Differential colonial characteristics of mycobacteria on oleic acid-albumin and modified corn meal agars. II. Investigation of rapidly growing mycobacteria. Zentralbl. Bakteriol. Parasitenk. Infektionskr. Hyg. Abt. Orig. 196:68-81.

13. Jones, W. D., Jr., and G. P. Kubica. 1965. The differential groupings of slowly growing mycobacteria based on their susceptibility to various dyes. Amer. Rev. Resp. Dis. 91:613-615.

14. Karlson, A. G., and E. F. Lessel. 1970. Mycobacterium bovis nom. nov. Int. J. Syst. Bacteriol. 20: 273-282.

15. Kestle, D. G., V. D. Abbott, and G. P. Kubica. 1967. Differential identification of mycobacteria. II. Subgroups of groups II and III (Runyon) with different clinical significance. Amer. Rev. Resp. Dis. 95:1041-1052.

16. Kilburn, J. O., V. A. Silcox, and G. P. Kubica 1969. Differential identification of mycobacteria. V. The tellurite reduction test. Amer. Rev. Resp. Dis. 99:94-100.

17. Koch, R. 1882. Die Aetiologie der Tuberkulose. Berl. klin. Wchschr. 19:221 (A translation from the German was prepared by Dr. and Mrs. Max Pinner to commemorate the 50th anniversary of the discovery of the tubercle bacillus; this was published in Amer. Rev. Tuberc. 25:285-323, 1932).

18. Kubica, G. P., and W. E. Dye. 1967. Laboratory methods for clinical and public health mycobacteriology. U.S. Pub. Health Serv. Pub. Health Monogr. no. 1547, Washington D.C.

19. Kubica, G. P., and W. D. Jones, Jr. 1965. Differential colonial characteristics of mycobacteria on oleic acid-albumin and modified corn meal agars. I. Investigation of slowly growing mycobacteria. Zentralbl. Bakteriol. Parasitenk. Infektionskr. Hyg. Abt. Orig. 196:53-67.

20. Kubica, G. P.. W. D. Jones, Jr., V. D. Abbott, R. E. Beam, J. O. Kilburn, and J. C. Cater, Jr. 1966. Differential identification of mycobacteria. I. Tests on catalase activity. Amer. Rev. Resp. Dis. 94:400-405.

21. Kubica, G. P., and G. L. Pool. 1960. Studies on the catalase activity of acid-fast bacilli. I. An attempt to subgroup these organisms on the basis of their catalase activities at different temperature and $p$ H. Amer. Rev. Resp. Dis. 81:387-391.

22. Liston, J., W. Wiebe, and R. R. Colwell. 1963. Quantitative approach to the study of bacterial species. J. Bacteriol. 85:1061-1070.

23. Oatway, W. H., Jr., and W. Steenken, Jr. 1936. The pathogenesis and fate of tubercle produced 
by dissociated variants of tubercle bacilli. J. Infec. Dis. 59:306-325.

24. Runyon, E. H. 1959. Anonymous mycobacteria in pulmonary disease. Med. Clin. N. Amer. 43:273-290.

25. Runyon, E. H., R. Bönicke, R. E. Buchanan, J. H. Hanks, W. Käppler, A. G. Karlson, H. H. Kleeberg, G. P. Kubica, A. Lind, D. A. Mitchison, S. R. Pattyn, W. B. Redmond, W. B. Schaefer, D. W. Smith, K. Takeya, R. L. Vollum, L. G. Wayne, E. Wolinsky, and G. P. Youmans. 1967. Mycobacterium tuberculosis, $M$. bovis and $M$. microti species descriptions, Zentralbl. Bakteriol. Parasitenk. Infektionskr. Hyg. Abt. Orig. 204:405413.

26. Runyon, E. H., M. J. Selin, and H. W. Harris. 1959. Distinguishing mycobacteria by the niacin test: a modified procedure. Amer. Rev. Tuberc. 79:663-665.

27. Steenken, W., Jr. 1935. The influence of the $p H$ on dissociation of B. Friedlander and $\mathrm{M}$. tuberculosis. J. Infec. Dis. 56:273-276.

28. Steenken, W., Jr. 1935. Lysis of tubercle bacilli in vitro. Proc. Soc. Exp. Biol. Med. 33:253-255.

29. Steenken, W., Jr., and L. U. Gardner. 1943. Vaccinating properties of avirulent dissociates of five different strains of tubercle bacilli. Yale J. Biol. Med. 15:393-402.

30. Steenken, W., Jr., and L. U. Gardner. 1946. History of H37 strain of tubercle bacillus. Amer. Rev. Tuberc. 54:62-66.

31. Steenken, W., Jr., V. Montalbine, and J. R. Thurston. 1959. The antituberculous activity of Kanamycin in vitro and in the experimental animal (guinea pig). Amer. Rev. Tuberc. 79:6671.

32. Steenken, W., Jr., W. H. Oatway, Jr., and S. A. Petroff. 1934. Biological studies of the tubercle bacillus. III. Dissociation and pathogenicity of the R. and $S$. variants of the human tubercle bacillus
(H31). J. Exp. Med. 60:515-540.

33. Stottmeier, K. D., R. E. Beam, and G. P. Kubica. 1967. Determination of drug susceptibility of mycobacteria to pyrazinamide in $7 \mathrm{H} 10$ agar. Amer. Rev. Resp. Dis. 96:1072-1075.

34. Stottmeier, K. D., G. P. Kubica, and C. L. Woodley. 1969. Antimycobacterial activity of rifampin under in vitro and simulated in vivo conditions. Appl. Microbiol. 17:861-865.

35. Szabo, I., and E. Vandra. 1963. Mycobacterium minetti (Penso et al, 1952). Bacteriological observations. Acta Microbiol. Acad. Sci. Hung. 10:215-223.

36. Tsukamura, M. 1967. Identification of mycobacteria. Tubercle 48:311-338.

37. Vestal, A. L., and G. P. Kubica. 1967. Differential identification of mycobacteria. III. Use of thiacetazone, thiophen-2-carboxylic acid hydrazide, and triphenyltetrazolium chloride. Scand. J. Resp. Dis. 48:142-148.

38. Virtanen, S. 1960. A study of nitrate reduction by mycobacteria. Acta Tuberc. Scand. Suppl 48.

39. Wayne, L. G., and J. R. Doubek. 1965. Classification and identification of mycobacteria. II. Tests employing nitrate and nitrite as substrate. Amer. Rev. Resp. Dis. 91:738-745.

40. Wayne, L. G., and J. R. Doubek. 1968. Diagnostic key to mycobacteria encountered in clinical laboratories. Appl. Microbiol. 16:925-931.

41. Wayne, L. G., J. R. Doubek, and R. L. Russell. 1964. Classification and identification of mycobacteria. I. Tests employing Tween 80 as a substrate. Amer. Rev. Resp. Dis. 90:588-597.

42. Wilson, G. S., and A. A. Miles. 1946. Topley and Wilson's principles of bacteriology and immunity. The Williams \& Wilkins Co., Baltimore.

43. Woodruff, C. D., D. Crombie, E. Medlar, J. S. Woodley, and W. Steenken. 1946. Report of the committee on evaluation of laboratory procedures. Amer. Rev. Tuberc. 54:428-432. 